\title{
Mars at war
}

\author{
Whether the climate of early Mars was warm and wet or cold and dry remains unclear, but the debate is \\ overheated. With a growing toolbox and increasing data to tackle the open questions, progress is possible if there is \\ openness to bridging the divide.
}

f one stumbles into a conference session on early Mars, it quickly becomes clear that the battle lines are drawn. On one side, scientists argue that early Mars was warm and wet beneath a thick greenhouse atmosphere. On the other side, scientists argue just the opposite: that Mars was cold and dry, with icy terrains transiently warmed just enough to allow liquid water to shape the surface. The result is an often entertaining, but frustrating debate. This month sees the latest rumble as Ramirez and Craddock throw down the gauntlet for a warm early Mars. With rovers analysing the ancient surface, the MAVEN orbiter studying the modern atmospheric evolution above, advances in climatemodelling capabilities, and the grwing appreciation of the value of interdisciplinary research, surely a consensus should be within reach. As with any hotly contested scientific question, the metaphorical digging in of heels rarely settles a debate. Instead, collaborations between Mars geologists and climatologists - and across the wet versus icy divide are needed to test a generation of fresh hypotheses that attempt to solve the early Mars conundrum.

The ancient terrains of Mars are puzzling. Mars is currently cold and dry with a thin atmosphere. But valley networks sculpted more than 3.5 billion years ago are strikingly similar in their geomorphology to terrestrial drainage networks. Landforms consistent with alluvial fans, deltas, lakes, and possibly even shorelines of an ancient ocean have been identified. Widespread clay minerals are also consistent with the presence of liquid water. But not only is Mars further from the Sun than Earth, but the early Sun is thought to have been dimmer than it is today. This poses a problem for explaining temperate climates even on early Earth, let alone on Mars, a problem known as the faint young Sun paradox.

We think that the early atmosphere of Earth was $\mathrm{CO}_{2}$-rich and fed by greenhouse gases degassed by widespread volcanism. A similar scenario has been invoked for Mars: a dense early atmosphere with high levels of $\mathrm{CO}_{2}$ or other greenhouse gases. But warming distant Mars under a faint young Sun is easier said than simulated.
Climate models can tell us what mixtures of atmospheric gases can keep the surface warm, but explaining the outgassing of such high levels of greenhouse gases, maintaining these conditions over an extended period of time, and explaining the subsequent loss of this early atmosphere are all problematic.

Climatologically, it is perhaps easier to suggest that early Mars was mostly cold. There is geological and geochemical evidence consistent with a cold and dry Mars, such as the rarity of carbonates and lack of glacial landforms at lower latitudes. Yet a cold Mars would seemingly have needed to be intermittently warmed to carve the valley networks and deposit sediments in basin lakes. Several mechanisms have been proposed to generate such intermittent warming, but finding a way of producing enough liquid water in the right places and for long enough to match geological constraints has proven tricky.

The debate between these two categories of interpretations is fierce. In 2016, Wordsworth reviewed the geological and climatological evidence and concluded that early Mars was probably cold with an intermittent hydrological cycle ${ }^{1}$. In a Perspective in this issue, Ramirez and Craddock review similar geological and climatological evidence and argue that the scenario most consistent with the available constraints is a warm and semi-arid Mars, albeit not quite as wet as in some earlier ideas with conditions not dissimilar to Earth's deserts (where it is still wet enough to rain). So which is it?

The debate is not a stagnant impasse that cannot be breached. Unlike many scientific conundrums that have hit a roadblock, especially those in planetary science which require the good fortune of a costly mission to test hypotheses, early Mars research is vibrant. New data are regularly streaming in from spacecraft at the Red Planet and there is a range of hypotheses to explore. These have included attempts to reconcile clay geochemistry with cold scenarios (for example, see ref. ${ }^{2}$ ), constraints on the loss of an early atmosphere from MAVEN data $^{3}$, and a methane burst mechanism for triggering intermittent warming ${ }^{4}$.

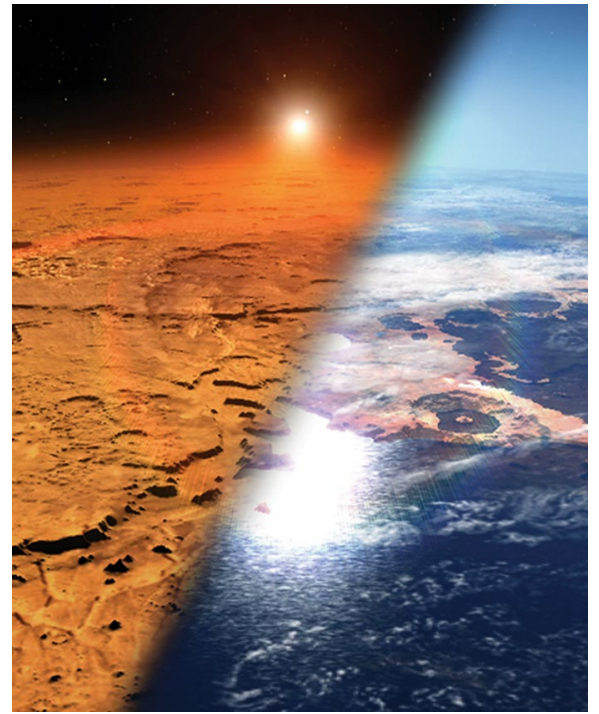

Artist's concept of a warm and wet early Martian environment (right) versus today's cold and dry planet (left). Credit: NASA's Goddard Space Flight Center.

While the data are streaming in, our toolbox is also expanding, with improved climate models for past Martian climates and an improved understanding of radiative transfer and clouds under Martian conditions. And there is an increasing push for those working with observational data and those working with numerical models to collaborate. Add to that renewed creativity by Mars researchers, and the ingredients to solve the faint young Sun paradox for Mars are all there. It is time to put aside the battle cries of 'warm and wet!' and 'cold and dry!' and instead stir the scientific pot with an open mind.

Published online: 4 April 2018 https://doi.org/10.1038/s41561-018-0107-7

\footnotetext{
References

1. Wordsworth, R. D. Annu. Rev. Earth Planet. Sci. 44 381-408 (2016)

2. Bishop, J. L. et al. Nat. Astron. 2, 206-213 (2018).

3. Jakosky, B. M. et al. Science 355, 1408-1410 (2017).

4. Kite, E. S. et al. Nat. Geosci. 10, 737-740 (2017).
} 